\title{
La guerra y la esclavización de los moriscos de las Alpujarras (enero a abril de 1569): el reino de Granada como mercado coyuntural de esclavos"
}

\author{
War and Enslavement of the Moriscos from \\ the Alpujarras (January to April 1569): the Kingdom \\ of Grenade as a Conjunctural Slave Market
}

\author{
Rafael M. Pérez García \\ Universidad de Sevilla \\ ORCID iD: https://orcid.org/0000-0002-3558-5104
}

\begin{abstract}
Este trabajo investiga el proceso de esclavización de los moriscos de las Alpujarras granadinas durante la campaña del marqués de Mondéjar en los primeros meses de la guerra de Granada. Para ello se utiliza documentación inédita conservada en el Archivo General de Simancas. El cruce de esta información con otra procedente de diferentes archivos municipales y notariales andaluces permite analizar cómo funcionó el mercado de esclavos moriscos durante los años 1569-1571, así como estudiar el proceso de exportación hacia las ciudades del valle del Guadalquivir de la población morisca granadina esclavizada.
\end{abstract}

Palabras clave: Esclavos moriscos; Alpujarras; 1569; mercado de esclavos; Andalucía.
This paper aims to analyse the enslavement of Moriscos from the Alpujarras during the initial months of the war of Grenade. This research is based on unknown historical records of the Archivo General de Simancas, which include a rich information about this issue. Other local and notarial sources treasured in several andalussian archives are also used in order to study the kingdom of Granada as a slave market during 1569-1571. These historical sources let to study the exports of Morisco slaves to the main cities of the Guadalquivir valley during these years.

Key words: Moriscos; Slaves; Alpujarras; 1569; Slave Market; Andalussia.

* Este trabajo se ha realizado en el marco del Proyecto de $\mathrm{I}+\mathrm{D}$ «Mercados y tratas de esclavos en el Atlántico ibérico del siglo XVI» (HAR2016-78056-P), financiado por el Ministerio de Economía, Industria y Competitividad del Gobierno de España.

Copyright: (C) 2020 CSIC. Este es un artículo de acceso abierto distribuido bajo los términos de la licencia de uso y distribución Creative Commons Reconocimiento 4.0 Internacional (CC BY 4.0). 


\section{La campaña del marqués de Mondéjar en las Alpujarras y la esclavización de los moriscos}

El estallido de la rebelión de los moriscos del reino de Granada a partir del día de Navidad de $1568^{1}$ dio lugar a la inmediata reacción de las autoridades castellanas en orden a suprimirla. Desde Granada, el marqués de Mondéjar, capitán general del reino, atacó las Alpujarras granadinas, mientras el ejército organizado por el marqués de Los Vélez entró en la parte oriental del reino manteniéndolo en orden y evitando la extensión de la guerra ${ }^{2}$. Los levantamientos de Istán ${ }^{3}$, en Málaga, y del río de Almería ${ }^{4}$, fueron sofocados con relativa celeridad, y desde Guadix se atacó el marquesado del Cenete, asimismo afectado por la rebelión ${ }^{5}$.

Este conjunto de operaciones militares desarrollado durante los dos primeros meses de la guerra, estuvo acompañado desde el primer momento por uno de los fenómenos más característicos de aquel conflicto, la esclavización generalizada de la población morisca. Así sucedió de forma masiva en el marquesado del Cenete ${ }^{6}$, o en las Alpujarras granadinas, como veremos. El comportamiento desordenado de los soldados entregándose al saqueo y a la esclavización de los moriscos pronto agravó la situación y complicó la guerra. El cronista Mármol no deja de apuntarlo una y otra vez, así, por ejemplo, tras la derrota del levantamiento de Istán, cuando los soldados enviados a Yunquera para mantener la paz, saquearon la villa «y cautivaron todas las mujeres moriscas ${ }^{7}$; o en Alboloduy y la taha de Marchena, donde los soldados

${ }^{1}$ Mármol, Historia, lib IV, caps. III-IV.

${ }^{2}$ Sobre la actuación del marqués de Los Vélez y su ejército, véanse Mármol, Historia, libro V, cap. V, y Sánchez Ramos, El II marqués de Los Vélez y la guerra contra los moriscos.

${ }^{3}$ Mármol, Historia, libro IV, caps. XXXV-XXXVI; Cabrillana, Marbella en el Siglo de Oro, pp. 221-231; Cabrillana, Moriscos y cristianos en Yunquera, pp. 100-106.

${ }^{4}$ Mármol, Historia, libro IV, cap. XXXVIII, y libro V, caps. III, XIII, XXII.

${ }^{5}$ Mármol, Historia, libro IV, cap. XXXVII, y libro V, caps. VI y XIV; Ruiz Pérez, "El levantamiento morisco", pp. 291-336.

${ }^{6}$ Dice Mármol que la milicia de Guadix tomó en el Cenete «dos mil almas captivas entre mujeres y niños, y mil bagajes cargados de ropa. Ésta fue una de las mejores presas que se hicieron en esta guerra y con menos peligro» (Mármol, Historia, libro V, cap. XIV). Estudiado concienzudamente por Garrido García, La esclavitud en el reino de Granada en el último tercio del siglo XVI: el caso de Guadix y su tierra.

${ }^{7}$ Mármol, Historia, libro IV, cap. XXXVI. 
del marqués de Los Vélez abandonaban su ejército «cargados de ropas, yendo bien proveídos de esclavas y de bagajes, se volvían a sus casas» ${ }^{8}$; y tras la victoria del marqués de Los Vélez el 1 de febrero de 1569 en Ohanes, donde «fueron captivas mil y seiscientas almas entre mujeres y niños, y el despojo de bagajes, cargados de ropas y joyas de precio, y de ganados, fue muy grande», después de lo cual «se fueron la mayor parte de los soldados con los despojos» ${ }^{9}$; en el peñón de Inox, tomado al asalto y organizado este como un auténtico negocio, donde se cautivaron «algunos moros» y 2.700 «mujeres y muchachos» ${ }^{10}$.

En este trabajo se ofrece información sobre la esclavización de los moriscos de las Alpujarras granadinas como consecuencia de la entrada del ejército de Mondéjar y su actuación durante los compases iniciales de la guerra. A pesar de que fue la principal campaña militar de la primera fase de la guerra, y de que dicho territorio fue uno de los escenarios por excelencia del conflicto en ésta y otras etapas de la misma ${ }^{11}$, lo cierto es que seguimos sabiendo poco acerca de la esclavitud de los moriscos de este territorio, y ello aunque fue, sin duda, uno de los más destruidos y afectados por la esclavización. Posiblemente pocas regiones del antiguo reino de Granada fueron sometidas a tan alto grado de desolación, masacre y destrucción de sus poblaciones humanas; la esclavitud no fue una causa secundaria de todo ello.

Como es bien sabido, tras producirse el levantamiento de las Alpujarras y el fracasado intento de extenderlo a la propia capital del reino, el marqués de Mondéjar y las autoridades del mismo procedieron a la inmediata organización de un ejército en la ciudad de Granada, solicitando auxilio «a las ciudades y señores de la Andalucía y reino de Granada». El ejército se formó con notable rapidez, entre los días 26 de diciembre de 1568 y 2 de enero de $1569^{12}$, agregándoseles las compañías de infantería y caballería de Antequera, Loja, Alhama, Alcalá la Real y Jaén ${ }^{13}$. Con este ejército, compuesto de 2.000 infantes y 400 hombres de caballería, además de diversos caballeros, salió de Granada

${ }^{8}$ Mármol, Historia, libro V, cap. XIII.

${ }^{9}$ Mármol, Historia, libro V, cap. XXVI.

${ }^{10}$ Mármol, Historia, libro V, caps. XXVII, XXVIII y XXXVI; Cabrillana, Almería morisca, pp. 241-247; Barrios Aguilera, "El morisco como botín", pp. 201-209.

${ }^{11}$ Sánchez Ramos, "La guerra de las Alpujarras (1568-1570)", pp. 507-542.

${ }^{12}$ Mármol, Historia, libro IV, cap. XXVI y XXXII.

${ }^{13}$ Mármol, Historia, libro V, cap. I. 
el marqués de Mondéjar de Granada el día 3 de enero de 1569 camino de las Alpujarras ${ }^{14}$. Durante los días siguientes, y en el transcurso de las operaciones militares para aplastar el levantamiento, se le fueron añadiendo las milicias de otras localidades, así como caballeros aventureros llegados de muy diversas procedencias: sabemos que en Dúrcal se encontraban las compañías de las Siete Villas de Granada (Montefrío, Íllora, Moclín, Colomera, Iznalloz, Montejícar y Guadahortuna), que entraron en combate la noche del 3 al 4 de enero de 1569'5; a Dúrcal llegaron al poco las milicias de Úbeda y Baeza, estando todavía allí el marqués de Mondéjar ${ }^{16}$; cuando el 10 de enero Mondéjar forzó el paso de Tablate y entró por fin en las Alpujarras, quedará allí de guarnición la infantería de Porcuna, poco después masacrada ${ }^{17}$; la liberación de Órgiva el día 12 de enero motivó al marqués de Mondéjar a escribir a la ciudad de Sevilla para «que no le enviase la gente de aquella ciudad ni la de la milicia de Sevilla, Gibraltar, Carmona, Utrera y Jerez», lo que explica que no participaran las tropas de estas localidades en esta primera campaña ${ }^{18}$, aunque al día siguiente se unieron a su ejército cuatro compañías de caballería e infantería de Córdoba, que habían llegado vía Granada ${ }^{19}$; también la milicia de Andújar participó en la campaña, quedando en Tablate para cubrir el hueco dejado por la aniquilación de los de Porcuna, y enseguida pudieron pasar por allí las tropas cordobesas de Aguilar, Montilla y Priego de Córdoba para unirse al ejército

${ }^{14}$ Mármol, Historia, libro V, cap. I. Según escribía un jesuita desde Granada el día 13 de enero, Mondéjar habría salido el 3 del mismo mes con poco más de 3.000 hombres, de los cuales 1.000 serían arcabuceros de Granada, y entre los otros se contarían los hombres de Antequera, Loja, Alhama, Alcalá la Real y Jaén (Vincent, "Les jesuites chroniqueurs", pp. 442 y 447).

${ }^{15}$ Mármol, Historia, libro V, cap. II.

${ }^{16}$ Mármol, Historia, libro V, cap. IV. Según un relato jesuita de la campaña de Mondéjar, este se detuvo en Dúrcal cuatro días, «aguardando gentes que le venían, y vinieron muchas de diversas partes, y muy adereçadas, [...]; y viéndose con mucha gente, embió los mill arcabuzeros a Granada y todos los de capa y espada» (Vincent, "Les jesuites chroniqueurs", p. 449).

${ }^{17}$ Mármol, Historia, libro V, caps. X y XII; Barrios Aguilera, "La guerra de los moriscos", pp. 418 y 419.

${ }^{18}$ Mármol, Historia, libro V, cap. X. El asunto de la participación de las tropas sevillanas en esta campaña y en la guerra se estudia por extenso en Fernández Chaves y Pérez García, En los márgenes de la Ciudad de Dios, pp. 59-82. No obstante, una semana más tarde se unieron al ejército de Mondéjar gente venida desde Sevilla, seguramente caballeros y aventureros por su cuenta y riesgo, así como otros de Ciudad Real y Madrid (Vincent, "Les jesuites chroniqueurs", p. 455).

${ }^{19}$ Mármol, Historia, libro V, cap. XI. 
del marqués en la Alpujarra ${ }^{20}$; asimismo, la caballería de Écija, con Tello de Aguilar, se sumó a las tropas del marqués de Mondéjar ${ }^{21}$. La estrategia fue sencilla, y el avance del ejército de Mondéjar a través de las Alpujarras posible gracias a una línea de abastecimiento sostenida desde Granada, donde el hijo del marqués, el conde de Tendilla, se encargaba de organizar y enviar mantenimientos, munición y las nuevas tropas que iban llegando desde diferentes lugares de Andalucía. La toma de Jubiles, con su correspondiente carnicería, marca un punto de inflexión en esta campaña ${ }^{22}$, y, el día 19 de enero, 16 alguaciles moriscos de las Alpujarras aceptaban rendirse al marqués ${ }^{23}$. Según Juan de Arquellada, para estas fechas el ejército de Mondéjar contaría ya con 13.000 hombres de a pie y de a caballo ${ }^{24}$, mientras que una semana antes, el día 12 de enero, al salir de Órgiva, apenas sobrepasaba los 8.000 , de ellos más de 3.000 tiradores $^{25}$, cifras que muestran el continuo y rápido engrosamiento de sus filas con las milicias andaluzas. El sometimiento de Las Guájaras ${ }^{26}$, que ocupó las dos primeras semanas del mes de febrero, prácticamente cierra esta campaña del marqués de Mondéjar ${ }^{27}$. Sin embargo, el comportamiento indisciplinado de las tropas, entregadas al pillaje y a la esclavización de los moriscos de las Alpujarras, contribuyó de manera decisiva, junto con otros factores (como las desavenencias entre Mondéjar y el marqués de Los Vélez), a reabrir el conflicto de manera virulenta entre marzo y abril de $1569^{28}$.

El cronista Luis del Mármol señala algunas pistas preciosas acerca de todo ello, indicando cómo mantener el orden en el ejército era una tarea tan importante o más que luchar contra los moriscos. Además, las cambiantes instrucciones del marqués de Mondéjar sobre la cues-

${ }^{20}$ Mármol, Historia, libro V, cap. XII.

${ }^{21}$ Mármol, Historia, libro V, cap. XXI. Detallada información sobre la organización de las tropas de Écija en la guerra y su participación en la misma en Sanz Fuentes, "Contribución de la ciudad de Écija”, pp. 983-999.

${ }^{22}$ Mármol, Historia, libro V, cap. XX.

${ }^{23}$ Sánchez Ramos, "La guerra de las Alpujarras", p. 518.

${ }^{24}$ Barrios Aguilera, "La guerra de los moriscos", p. 419.

${ }^{25}$ Vincent, "Les jesuites chroniqueurs", p. 450.

${ }^{26}$ Mármol, Historia, libro V, cap. XXV, XXIX-XXXI.

${ }^{27}$ Un mapa donde puede seguirse cronológicamente la campaña de Mondéjar en las Alpujarras entre enero y marzo de 1569 se halla en la edición de Javier Castillo de la Historia de Mármol, p. 758.

${ }^{28}$ Sánchez Ramos, "La guerra de las Alpujarras", pp. 520-521; Aranda Doncel, Los moriscos en tierras de Córdoba, p. 129. 
tión de la esclavitud de los moriscos contribuyeron al desorden general. El temprano descontrol queda de manifiesto en el hecho de que la infantería de Porcuna que quedó guarneciendo el estratégico paso de Tablate, entrada de las Alpujarras, tenía como objetivo primordial impedir la huida de los desertores y confiscarles el botín de guerra: su capitán Pedro de Arroyo estaba allí «con orden que no dejase pasar los soldados que se iban del campo sin licencia [...] su fin solo era salir al paso a los soldados que se iban del campo sin licencia, para quitarles, por de contrabando, los ganados, las esclavas y los bagajes que llevaban $\rangle^{29}$. En efecto, el avance de las tropas del ejército de Mondéjar fue acompañado de un saqueo salvaje que las órdenes en contra, cuando existieron, fueron incapaces de detener. De hecho, a partir de un determinado momento, cuando la entrada en combate se hizo inminente, el propio marqués utilizó el señuelo del pillaje para estimular a sus tropas: el día 12 de enero, al pasar el puente de Órgiva y penetrar definitivamente en territorio enemigo, donde se esperaban duros enfrentamientos con los moriscos, «el marqués de Mondéjar, yendo a entrar con su campo en la Alpujarra, para animar los soldados que iban sin sueldo, había mandado echar un bando al pasar de la puente de Órgiva, declarando que la guerra era contra enemigos de la fe y rebeldes a Su Majestad, y que se había de hacer a fuego y a sangre» ${ }^{30}$ : según el derecho de la época, la declaración de los moriscos como enemigos de la fe abría la puerta a su esclavización ${ }^{31}$. Ello explica por qué, al día siguiente, el 13 de enero, tras llegar a Bubión, «los soldados subieron en cuadrillas por la sierra arriba, y captivando muchas mujeres y niños, mataron los hombres que pudieron alcanzar, y les tomaron gran cantidad de bagajes cargados de ropa y de seda, que llevaban a esconder por aquellas breñas $\rangle^{32}$. El 18 de enero, tras tomar el castillo de Jubiles, «donde [los moriscos] tenían recogidas las mujeres y la riqueza de aquellas tahas», el marqués «les dio [a los soldados] a saco todo el mueble, en que había ricas cosas de seda, oro, plata y aljófar», capturándose 300 hombres y 2.100 mujeres; recluidos en la iglesia de Jubiles

\footnotetext{
${ }^{29}$ Mármol, Historia, libro V, cap. XII.

${ }^{30}$ Mármol, Historia, libro V, cap. XXXII. Sobre el paso por Órgiva, Mármol, Historia, libro $\mathrm{V}$, cap. X.

${ }^{31}$ Pérez García, "El laboratorio ibérico de conceptos y prácticas sobre la esclavitud", pp. 11-38.

${ }^{32}$ Mármol, Historia, libro V, cap. XI.
} 
los que cupieron, y quedando un millar «en la placeta que estaba delante de la puerta», aquella noche tuvo lugar una confusa matanza («mataron en un instante cuantas hallaron fuera de la iglesia») que degeneró en motín de la soldadesca, «indignados los soldados por un bando que se había echado aquel día, en que mandaba el marqués que no se tomase ninguna mujer por captiva, porque eran libres $\rangle^{33}$. Es decir, el bando del 12 de enero permitiendo la esclavización de los moriscos fue suspendido sólo seis días más tarde, cuando la victoria militar era evidente y el marqués consideró oportuno complementarla con una oferta de paz a los rebeldes. Existían para ello razones jurídicas de peso, dado que por el momento, y hasta la primavera, y solo después de arduos debates en distintas instancias civiles y eclesiásticas, no existiría una decisión regia clara y positiva respecto a la legalidad de la esclavización de los moriscos granadinos ${ }^{34}$.

La promesa dada a los moriscos de conservarles la libertad constituía uno de los pilares de la estrategia de pacificación del marqués de Mondéjar, que empezó a dar sus frutos el 19 de enero, como vimos, cuando los alguaciles alpujarreños aceptaron «reducirse» y entregar las armas. Pero la codicia por capturar a los moriscos como esclavos generaba importantes tensiones dentro del propio ejército del marqués, condicionando cada día que pasaba el curso de las operaciones militares. El 28 de enero, los capitanes de caballería que se encontraban en Laujar de Andarax disputaron con el capitán Álvaro Flores, representante del marqués, porque querían «tomar por esclavos todos los moros y moras que se habían venido a guarecer en las casas de los reducidos, diciendo que no se entendía con ellos la salvaguardia y Álvaro Flores se lo había contradicho con la orden que llevaba del marqués para conservar los que se hubiesen ya reducido y todos los que se viniesen a reducir, el cual mandó que no tocasen en los unos ni en los otros, sino que los dejasen estar libremente en sus casas, sin darles pesadumbre» ${ }^{35}$;

${ }^{33}$ Mármol, Historia, libro V, caps. XVIII-XX. Arquellada reduce el número de moriscas capturadas en Jubiles, diciendo «que serían cantidad de mill, poco más» (Barrios Aguilera, "La guerra de los moriscos", p. 419). Nunca sabremos con exactitud lo que sucedió en Jubiles aquella noche; el jesuita Gaspar de Aranda, que escribe desde Granada el 13 de marzo de 1569, poco después de los hechos, da a su vez su propia versión de lo ocurrido, avisando de que «esta historia se cuenta de tres o quatro maneras» (Vincent, "Les jesuites chroniqueurs", pp. 451-452).

${ }^{34}$ La cuestión ha sido estudiada en Benítez Sánchez-Blanco, "El cautiverio de los moriscos", pp. 19-43 y en Pérez García y Fernández Chaves, "La guerra de Granada entre guerra civil y «guerra justa»”, pp. 229-247. Véase también Mármol, Historia, libro V, cap. 32. 
el clima de tensión y descontento dentro del ejército nos lo señala claramente la suspensión al día siguiente, 29 de enero, por orden de Mondéjar, de una operación en Ohanes por tener escaso valor militar y porque «solamente sirviera aquella ida de dar que robar a los soldados y hacer que captivasen gente inútil $»^{36}$. Finalmente, y como parte de la misma estrategia de apaciguamiento, el marqués de Mondéjar comenzó a liberar a las moriscas capturadas: así a finales de enero en Ugíjar, cuando mandó «entregar mil moriscas de las que habían quedado vivas en Jubiles y captivádose después en Paterna» a tres alguaciles moriscos reducidos de las Alpujarras, «con orden que las diesen a sus maridos, padres y hermanos, y les notificasen que las tuviesen en depósito para volverlas cada y cuando que les fuesen pedidas $\rangle^{37}$.

No obstante, el planteamiento negociador de Mondéjar acabó fracasando como consecuencia, precisamente, de la descomposición de su propio ejército y del pillaje a que los soldados comenzaron a someter por su cuenta el territorio, incluyendo aquellos pueblos que se habían colocado bajo la salvaguarda y amparo del marqués a cambio de abandonar las armas. Todo esto sucedió entre mediados de febrero de 1569, en que el marqués con su ejército regresó a Órgiva desde Las Guájaras ${ }^{38}$, y comienzos de abril, en que recibió y cumplió la orden de volver a Granada para ser relevado del mando por el hermano del rey, don Juan de Austria $^{39}$. Allí, en Órgiva, fue recibiendo el marqués «todos los lugares de la Alpujarra por sus alguaciles y regidores o por sus procuradores», pero enseguida «cuadrillas de soldados desmandados» comenzaron a robar a los moriscos que se reducían, capturando «muchachos» y a todos aquellos que podían, actos que con frecuencia degeneraban en enfrentamientos violentos con muertes. Los esfuerzos del marqués por controlar a sus tropas acabaron resultando inútiles, así como los intentos de capturar al líder morisco Aben Humeya ${ }^{40}$. El saqueo de Laroles el 1 de

${ }^{35}$ Mármol, Historia, libro V, cap. XXV.

${ }^{36}$ Mármol, Historia, libro V, cap. XXV.

${ }^{37}$ Mármol, Historia, libro V, cap. XXV. Según Arquellada, Mondéjar habría ordenado llevar unas 800 moriscas a Los Válores «hasta que su señoría mandase otra cosa, dexando con ellas algunos moros de paz que el marqués bien conoçía» (Barrios Aguilera, "La guerra de los moriscos", p. 419).

${ }^{38}$ Mármol, Historia, libro V, cap. XXXIII.

${ }^{39}$ Mármol, Historia, libro VI, caps. IV y V.

${ }^{40}$ Mármol, Historia, libro V, caps. XXXIII-XXXIV. Arquellada también tomó nota del comportamiento descontrolado de las tropas de Mondéjar cuando recordaba que «salían 
marzo (pueblo que, a pesar de haberse reducido, fue quemado, su población masculina masacrada y las mujeres esclavizadas por tropas procedentes de la fortaleza de La Peza y dependientes del conde de Tendilla) marca un hito decisivo en el fracaso de la política de Mondéjar, como así lo entendió él mismo enseguida ${ }^{41}$ y lo valoraron los propios moriscos, que ya no se fiarían más de sus promesas ${ }^{42}$. Mármol comenta de las moriscas de Laroles: «las indefensas mujeres perdieron su libertad y fueron vendidas por esclavas $\rangle^{43}$. Es evidente que el descontento de los soldados y el descontrol general de la situación acabaron haciendo naufragar todos los planes de Mondéjar; un jesuita, el P. Navarro, escribía meses más tarde refiriéndose a aquellas semanas decisivas:

«Nuestros soldados, no pudiendo çufrir el estar quedos y sin paga, sino con una muy mísera y triste comida, contra todo bando y contra toda orden y diligencias que se hazían, se ivan unos por un cabo y otros por otro a los lugares que tenían salvaguardia del marqués, y les tomavan las mugeres y las hijas, y les robavan lo que podían, y los moros viendo esto se defendían y matavan a los nuestros, y murieron desta manera contra orden y bando más de tres mil hombres; y como a los que ivan contra bando los castigavan y quitavan quanto trayan por castigo de su desobediencia, venían a Granada diçiendo grandes y notables males del marqués de Mondéjar, y muchos y muy grandes falsos testimonios, los quales como los creieron al principio todos o casi todos los de esta çiudad y toda la Andaluzía, y Castilla, y España, y fuera de España, quando entró aquí en Granada, la víspera de pascua de resurrectión, no faltava sino apedrealle, y creieron, como digo, chancillería y ciudad tantas cosas y tan malas, y escrivéronlas al rey y consejo, que acordó S. M. de embiar aquí al Sr. Dn. Joan de Austria, y al duque de Sesa $[\ldots] \gg^{44}$.

Día tras día durante el mes de marzo de 1569, el plan de Mondéjar se derrumbaba de forma estrepitosa, llegando rápidamente las noticias de su fracaso a la corte. Según Mármol, una carta del 17 de marzo habría ya ordenado a Mondéjar dejar el ejército de la Alpujarra para ser sustituido por don Juan de Austria ${ }^{45}$. Mientras este llegaba, Mondéjar continuó en Órgiva. Su pretensión de recuperar a las moriscas devueltas que habían quedado en situación de «depósito» acabó por desestabilizar la situación. De nuevo, el relato de Mármol es insustituible:

los cristianos a correr la tierra de secreto, sin liçençia del general» (Barrios Aguilera, "La guerra de los moriscos", p. 420).

${ }^{41}$ Mármol, Historia, libro V, cap. XXXV.

${ }^{42}$ Mármol, Historia, libro VI, caps. I y II.

${ }^{43}$ Mármol, Historia, libro V, cap. XXXV.

${ }^{44}$ Vincent, "Les jesuites chroniqueurs", p. 464.

${ }^{45}$ Mármol, Historia, libro V, cap. XXXVII. 
«En este tiempo mandó el marqués de Mondéjar notificar a los moriscos depositarios de las esclavas de Jubiles que las llevasen luego a Órgiva; y Miguel de Herrera sacó cuatrocientas dellas de poder de sus maridos, padres y hermanos, y las llevó a entregar; y como los factores del marqués le apretasen para que las entregase todas, viendo que sería imposible poderlas dar, porque algunas se habían muerto, y otras las habían captivado de nuevo los soldados que andaban desmandados sin orden, por excusar su vejación, trató de componerse por todas las de la taha de Ferreira; y se efectuara si se pusieran con él en una cosa convenible, porque el moro daba veinte ducados por cabeza, y las personas a quien se cometió el negocio no quisieron menos de a sesenta ducados por cada una. $\mathrm{Y}$ al fin hubo de traer las que pudo recoger, y se vendieron muchas dellas en Granada en pública almoneda por cuenta de Su Majestad, y otras murieron en captiverio» ${ }^{46}$.

Curiosamente, este mismo asunto vuelve a reaparecer en el momento crucial que marca el fracaso definitivo de Mondéjar. Con el objeto de apresar a Aben Humeya y al Zaguer, líderes de la rebelión, el marqués envió al capitán Álvaro Flores con un millar de hombres a Válor. Tenía una segunda misión: «También se entendió que mandó a Álvaro Flores que pidiese a los regidores [moriscos] le entregasen las moriscas de Su Majestad, que se les habían dado en depósito en Jubiles, y que las llevase a Órgiva, donde se recogían las demás». Intuyendo el carácter de cacería de la incursión, los mercaderes de personas se unieron a la misma a fin de comprar barato los esclavos: «otros que los siguieron después sin orden entendiendo que iban a hacer algún buen efeto, y algunos aventureros que llevaban cantidad de dineros para emplear en esclavas, ropa y joyas; porque en semejantes jornadas que éstas siempre tenían los soldados aprovechamiento de buena o de mala guerra y hallando al pie de la obra quien se lo comprase, lo daban por poco dinero». Salieron de Órgiva el 30 de marzo, y la noche del 2 de abril cayeron sobre Válor, «matando cuantos moros les venían por delante, saquearon las casas, captivaron las mujeres». En la retirada durante el 3 de abril, llevando más de 1.200 moriscas, las tropas fueron emboscadas y masacradas: murió Flores y «todos perecieron». Y apostilla Mármol que los moriscos «se satisficieron bien del daño recebido en Laroles ${ }^{47}$. En realidad, la situación estaba totalmente fuera de control

${ }^{46}$ Mármol, Historia, libro V, cap. XXXIII.

${ }^{47}$ Mármol, Historia, libro VI, cap. I. Según Arquellada, las moriscas habrían sido 800, y solo catorce los soldados que escaparon con vida (Barrios Aguilera, "La guerra de los moriscos", p. 422). 
y la rebelión se había avivado de forma imparable. Las acciones y depredaciones de las tropas no tenían freno, y la reacción de los moriscos fue todo lo contundente que pudieron. El 5 de abril los soldados saquearon y quemaron Turón, esclavizando a «todas las mujeres y niños» ${ }^{48}$; también Molvízar fue saqueado y sus mujeres esclavizadas aquellos días; en otros lugares, los ataques fracasaban y los soldados acababan degollados en masa, como en Bayárcal y otras partes ${ }^{49}$. La guerra se reactivaba mientras Mondéjar abandonaba, impotente, Órgiva. De nuevo fueron llamadas las tropas de Sevilla y de otras partes de Andalucía. El 14 de abril entraba don Juan de Austria en Granada, siendo recibido por el marqués de Mondéjar y el conde de Tendilla ${ }^{50}$. Terminaba definitivamente una etapa de la guerra y el primer episodio de la esclavización de los moriscos de las Alpujarras ${ }^{51}$.

\section{Registros de esclavos moriscos en las Alpujarras durante el primer trimestre de 1569}

\subsection{Nueva información documental}

Más allá de la existencia de las cartas de compraventa de moriscos como esclavos otorgadas durante las primeras semanas y meses de la guerra, que se conservan en diferentes archivos notariales andaluces y que solo nos ofrecen datos particulares, hasta la fecha apenas disponíamos para el conocimiento de la esclavización de los moriscos de las Alpujarras durante la campaña de Mondéjar de las cifras globales que se pueden espigar en las obras de los cronistas de la guerra, fundamentalmente Mármol y Hurtado de Mendoza. En el presente trabajo presentamos la información contenida en una Relación sacada de los registros que pasaron ante diferentes escribanos el año de la guerra de los esclavos y esclavas que se registraron, quel quinto dellos pertenece a Su Majestad, la qual se a sacado para cobrallos de las personas

${ }^{48}$ Mármol, Historia, libro VI, cap. II.

${ }^{49}$ Mármol, Historia, libro VI, cap. III.

${ }^{50}$ Mármol, Historia, libro VI, caps. IV y V. Mondéjar habría salido de Órgiva el día 8 de abril (Aranda Doncel, Los moriscos en tierras de Córdoba, p. 129).

${ }^{51}$ Sobre el ocaso del poder de los Mendoza en Granada, véanse Spivakovsky, "Un episodio de la guerra contra los moriscos", Cepeda Adán, "Los últimos Mendoza" y Jiménez Estrella, Poder, ejército y gobierno en el siglo XVI, pp. 162-189. 
que en cada partida se declara ${ }^{52}$, conservada en el Archivo General de Simancas, y que arroja importante luz sobre todo el asunto.

El motivo de la elaboración de este documento es el cobro del quinto real correspondiente a la Hacienda de Felipe II, de modo que la Relación está realizada específicamente para exigir el pago del mismo a aquellas personas que se acabaron convirtiendo en propietarias de los moriscos esclavizados; de ahí que extracte de los registros redactados previamente por diferentes escribanos, los nombres tanto de las personas que los registraron ante los mismos como los de aquellas otras, en caso de ser diferentes, que se hicieron cargo como depositarios de los moriscos esclavizados. Esto significa que a partir de los registros de nueve escribanos ${ }^{53}$ se ha redactado un documento diferente (la Relación, así nos referiremos en adelante a este documento) que, dada su finalidad fiscal, eliminó numerosos datos personales referidos a los moriscos consignados en los registros originarios de los escribanos, especialmente su edad y procedencia; son los datos del nombre y vecindad de registrador y depositario los que más interesaban, dado que a ellos habría que buscar para exigir el pago del quinto real. Los escribanos redactaron estos registros entre enero y abril de 1569, correspondiendo, pues, sin duda, a la primera fase de la guerra en las Alpujarras. Solo conocemos de forma muy parcial la cronología de la elaboración de estos registros, a partir de datos puntuales contenidos en la propia $R e-$ lación. En la tabla 1 los presentamos.

\footnotetext{
${ }^{52}$ Archivo General de Simancas (en adelante AGS): Contaduría Mayor de Cuentas Primera Época (en adelante CMC-I), leg. 1913, doc. 6.

${ }^{53}$ Sus nombres los presentamos en la tabla 1 (vid infra), y no coinciden con los de los escribanos de las Alpujarras, quienes, además, fueron asesinados prácticamente en su totalidad por los moriscos; las escribanías públicas del número de la Alpujarra, que eran seis en esta época y se hallaban en la plaza pública de Ugíjar, fueron también destruidas por los sublevados al comienzo de la rebelión (De la Obra Sierra y Osorio Pérez, "Los escribanos de las Alpujarras"). Así pues, pensamos que estos nueve escribanos debieron llegar con las tropas, salvo quizás Blas Dorantes, del que se afirma que era de la propia Ugíjar; además, los nombres de tres de ellos (Diego del Arroyo, Jerónimo de Castro y Juan Pérez) nos inducen a sospechar que pudieran pertenecer a familias de escribanos públicos de la ciudad de Granada (García Pedraza, Inventario de Protocolos Notariales. Granada, siglo $X V I$, pp. 108, 110, 119); Luis de Ribera, finalmente, quizás sea el mismo que ocupara casi dos décadas antes la escribanía mayor del juzgado de Ugíjar y que después pasó a disfrutar de una escribanía del número de Granada (De la Obra Sierra y Osorio Pérez, "Los escribanos de las Alpujarras").
} 
Tabla 1

Los escribanos y la elaboración de los registros de esclavos moriscos en las Alpujarras según la Relación (enero a abril de 1569).

\begin{tabular}{|l|c|c|c|}
\hline Nombre del escribano & Localidad del escribano & $\begin{array}{c}\text { Fecha primer } \\
\text { registro }\end{array}$ & $\begin{array}{c}\text { Fecha último } \\
\text { registro }\end{array}$ \\
\hline Andrés Ruiz de Carrión & - & 22 de enero & 23 de enero \\
\hline Juan Pérez Hurtado & - & 23 de enero & 13 de febrero \\
\hline Blas Dorantes & Ugíjar de las Alpujarras & 30 de enero & 13 de febrero \\
\hline Diego del Arroyo & - & 31 de enero & 22 de abril \\
\hline Jerónimo de Castro & - & 7 de febrero & 10 de marzo \\
\hline Luis de Ribera & - & 17 de febrero & 6 de abril \\
\hline Juan Pérez & - & - & - \\
\hline Juan Pérez Maldonado & - & - & - \\
\hline Sebastián de Bar (sic) & - & - & - \\
\hline
\end{tabular}

Las fechas apuntadas en la tabla 1 no tienen por qué indicar necesariamente con exactitud el comienzo y el final de la actividad de dichos escribanos, dado que la Relación solo ofrece esta información de forma fragmentaria, y en el caso de tres de los escribanos no la aporta en absoluto. Sin embargo, el hecho de haber sido incluida toda la información de los registros en la misma Relación indica que pertenecen a una misma cronología. Ello nos permite utilizar esta Relación como un documento testigo para el análisis de la primera fase de la esclavización de los moriscos del reino de Granada, en concreto los correspondientes a las Alpujarras. Evidentemente no tenemos por qué estar ante un listado exhaustivo de todos los moriscos esclavizados en aquella geografía y fase del conflicto, pues desconocemos si existieron otros registros de escribanos, pero sí resulta suficientemente ilustrativo del fenómeno que estudiamos.

Especial interés guarda un listado individualizado que cierra la propia Relación, intitulado de la siguiente forma: Sacáronse estos diez pliegos del Registro quinto desclavos y esclavas que se registraron en la villa de Uxíxar de las Alpujarras y en la de Órjiba el año pasado de dlxix [1569] el qual quedó con los demás registros de donde se sacaron los pliegos antecedentes a éstos para cobrar los quintos dellos. Este corresponde a los esclavos recogidos por Blas Dorantes, escribano de 
Ugíjar en las Alpujarras, y nos permite seguir su recorrido registrando esclavos por las Alpujarras sometidas: así, del 31 de enero al 4 de febrero hizo su registro en Ugíjar, para continuar desde el 5 de febrero al día 7 del mismo mes en Órjiva; en 13 de febrero registraba en Las Guájaras, al día siguiente de haber sido tomado su fuerte por las tropas del marqués: el hecho de que solo hiciese un registro en esta última localidad se debe explicar por la matanza general que ordenó realizar allí el marqués de Mondéjar ${ }^{54}$.

Las importantes diferencias existentes entre los registros de tales escribanos, especialmente en lo que se refiere al número de esclavos moriscos que cada uno registró (véase tabla 2) y hasta donde podemos reconstruirlos a partir de la Relación, nos avisan de su carácter parcial. $\mathrm{O}$ al menos eso pensamos. En cualquier caso, no cabe duda de que ofrecen una información preciosa para el estudio del proceso de captura y del funcionamiento en primera instancia de aquel territorio como improvisado y coyuntural mercado de esclavos.

Tabla 2

Número de moriscos esclavizados registrados por cada escribano según la Relación, 1569

\begin{tabular}{|l|c|}
\hline \multicolumn{1}{|c|}{ Escribano } & Número de esclavos moriscos \\
\hline Andrés Ruiz de Carrión & 11 \\
\hline Juan Pérez Hurtado & 242 \\
\hline Blas Dorantes & 210 \\
\hline Diego del Arroyo & 570 \\
\hline Jerónimo de Castro & 120 \\
\hline Luis de Ribera & 85 \\
\hline Juan Pérez & 30 \\
\hline Juan Pérez Maldonado & 16 \\
\hline Sebastián de Bar (sic) & 2 \\
\hline TOTAL & 1.286 \\
\hline
\end{tabular}

${ }^{54}$ «Fue tanta la indignación del marqués de Mondéjar, que, sin perdonar a ninguna edad ni sexo, mandó pasar a cuchillo hombres y mujeres cuantos había en el fuerte, y en su presencia los hacía matar a los alabarderos de su guardia, [...]» (Mármol, Historia, libro V, cap. XXXI). Arquellada confirma la masacre: «Y ansí ganado el fuerte, mandó el marqués que matasen todas aquellas moras y muchachos que allí estavan» (Barrios Aguilera, "La guerra de los moriscos", p. 422). 
2.2. El grupo morisco esclavizado en las Alpujarras entre enero y abril de 1569 según la Relación: una primera caracterización

En la Relación se listan un total de 1.286 moriscos, de ellos 325 son hombres $(25,3 \%)$ y 795 mujeres $(61,8 \%)$, desconociendo del resto de individuos su sexo (166 casos, 12,9\%). Con frecuencia, este último grupo está compuesto por hijos de los anteriores, especialmente moriscas que llevan «una cría» o «una cría a los pechos» o se registran «con su crianza». La Relación apenas contiene referencias a la edad de los moriscos, y en ocasiones menciona grupos como aquel de «diez esclavos chicos y grandes», otro de esclavas «grandes y chicas», o «cinco esclavas, las tres grandes y las dos pequeñas», o aquel de «cuatro esclavas, la una dellas pequeña y las demás grandes»; aparecen calificativos como «esclavillo» y abunda el de «muchacho» o «muchacha». Por todo ello no es posible caracterizar de forma precisa a esta población esclava en función de la variable edad. Las raras menciones a edades exactas suelen estar relacionados con niños, de los que encontramos una docena con edades especificadas y comprendidas entre uno y doce años. De todos estos datos se puede inferir que la población infantil y adolescente esclavizada era cuantiosa, tal y como afirman las crónicas y confirman los estudios locales sobre población morisca en Andalucía realizados en base a documentación notarial. La relación entre sexos (más o menos cercana a 3 mujeres por cada hombre, aproximadamente) ya predice la que será una constante de los grupos moriscos esclavizados durante la guerra y entre las poblaciones constituidas en las ciudades de destino, como Granada o Sevilla, entre otras ${ }^{55}$.

También es parca la Relación en datos concretos de procedencia de estos moriscos. Solo del morisco y de las seis moriscas registrados por Francisco de Palomares, sargento mayor del ejército, sabemos que una era de Pitres de Ferreira y cinco individuos de Andarax. No obstante, las fechas y lugares del registro así como la identificación de numerosos registradores, miembros del ejército de Mondéjar, señalan la Alpujarra de forma general como lugar de origen, hecho confirmado en algunos casos, como veremos, por documentación notarial complementaria.

\footnotetext{
${ }^{55}$ Fernández Chaves y Pérez García, En los márgenes de la Ciudad de Dios, p. 109; Martín Casares, La esclavitud en la Granada del siglo XVI, pp. 238-239. Una reciente y valiosa revisión de conjunto en Garrido García, "Las esclavas moriscas".
} 


\section{Los moriscos, presa de las tropas: primeros repartos, mercados de esclavos y lógicas de redistribución espacial hacia la Anda- lucía bética}

La procedencia de las tropas del ejército de Mondéjar queda reflejada en el estudio del origen geográfico (vecindad) de los individuos que registraron ante notario los moriscos apresados, y que se convirtieron en la mayoría de los casos en depositarios de los mismos (dado que todavía no se había dictaminado sobre la situación legal de esclavitud para los mismos, ya sabemos que teóricamente solo se encontraban en situación de depósito). En la tabla 3 presentamos estos datos agrupados por territorios y provincias actuales, poniéndose de manifiesto el abrumador predominio de los procedentes de territorios granadinos, cordobeses y jiennenses, que alcanzan dos terceras partes del total de moriscos registrados. Esta información resulta extremadamente interesante dado que las tropas (los captores) actuaron como primer vector de difusión y exportación de los moriscos capturados fuera del reino de Granada, funcionando la ciudad de Granada como una gran almoneda ${ }^{56} \mathrm{y}$ convirtiéndose las rutas de regreso de los soldados hacia sus hogares y sus localidades de destino en los puntos receptores por excelencia de tan gran cantidad de moriscos ${ }^{57}$, primero en situación de depósito, y después como esclavos o administrados (en el caso de los niños contemplados en la legislación real) ${ }^{58}$. Ello nos ayuda a comprender el alto número de moriscos esclavos vendidos en las ciudades de Jaén $^{59}$ y de Córdoba ${ }^{60}$ durante la guerra. De modo que la Relación se constituye en un documento clave para comprender la posterior distribución de los esclavos moriscos de las Alpujarras hacia la Andalucía del Guadalquivir y al norte de Sierra Morena.

\footnotetext{
${ }^{56}$ Martín Casares, La esclavitud en la Granada del siglo XVI.

${ }^{57}$ Fernández Chaves y Pérez García, En los márgenes de la Ciudad de Dios, pp. $97-$ 108.

${ }^{58}$ Sobre esta última cuestión, véase Pérez García y Fernández Chaves, "La infancia morisca, entre la educación y la explotación", pp. 149-186.

${ }^{59}$ Aranda Doncel, "Los esclavos en Jaén durante el último tercio del siglo XVI", pp. 233-251.

${ }^{60}$ Aranda Doncel, Los moriscos en tierras de Córdoba, pp. 137-173.
} 
Tabla 3

Territorios de procedencia de los registradores de los esclavos moriscos según la Relación ${ }^{61}$

\begin{tabular}{|l|c|c|}
\hline \multicolumn{1}{|c|}{ Provincia/Territorio } & $\mathbf{N}^{\mathbf{0}}$ esclavos moriscos & \% \\
\hline Granada & 542 & 42,15 \\
\hline Málaga & 179 & 13,92 \\
\hline Almería & 10 & 0,78 \\
\hline Jaén & 229 & 17,8 \\
\hline Córdoba & 99 & 7,7 \\
\hline Sevilla & 46 & 3,6 \\
\hline Cádiz & 1 & 0,07 \\
\hline Murcia & 6 & 0,46 \\
\hline Submeseta sur & 24 & 1,87 \\
\hline Submeseta norte & 9 & 0,7 \\
\hline Otros / Sin indicación de vecindad & 141 & 11 \\
\hline Total & 1.286 & 100 \\
\hline
\end{tabular}

Lo dicho se pone todavía más de manifiesto cuando atendemos a las poblaciones concretas de procedencia de los registradores/depositarios (futuros primeros propietarios) de los moriscos (Anexo: Tabla 4). En efecto, los de la ciudad de Granada se apropiaron de más del $30 \%$ del total de la presa, y los de las otras ciudades cuyas milicias jugaron un papel relevante en la campaña de Mondéjar fueron precisamente los más beneficiados: los de Antequera se hicieron casi con el 7,5\%, los de Córdoba con el 5,2\%, los de Baeza y Úbeda acapararon casi el 9\%, los de Loja y Alhama el 3,3\%, etc. En la larga lista de casi un centenar de localidades de origen, son precisamente aquellas que aportaron compañías y tropas organizadas las que más descuellan (Vélez-Málaga, Motril, Jaén, Alcalá la Real y Martos han de unirse al grupo anterior). La presencia de contados registradores oriundos de muchos otros lugares se debe bien a su integración entre las compañías de las poblaciones que acabamos de señalar, bien a su participación in-

${ }^{61}$ La información de vecindad contenida en la Relación se ha completado en ocho casos de esclavos gracias a la identificación de los registradores en la crónica de Mármol. 
dividual como caballeros o aventureros, bien por tratarse de individuos naturales del propio territorio expoliado y que capturaron a sus propios vecinos moriscos (son los casos de aquellos procedentes de las propias Alpujarras, como los de Órgiva o Ugíjar ${ }^{62}$ ), como tantas veces sucedió en esta guerra ${ }^{63}$. Al mismo tiempo, la irrelevancia numérica de los registradores originarios de localidades de las actuales provincias de Sevilla y Cádiz se explica por la no participación de las milicias de éstas en la campaña de Mondéjar. Ello se refleja también en el estudio del mercado de esclavos de la ciudad de Sevilla, que se activó de manera espectacular durante 1569-1571 gracias al aporte de los moriscos ${ }^{64}$ : el primer morisco vendido en la ciudad que hemos podido documentar lo fue el 5 de enero de $1569^{65}$, pero fueron contadísimos los que llegaron antes de los últimos días de febrero, y éstos procedentes en su mayoría del Cenete; a pesar de ello, como veremos, no faltaron los de las Alpujarras $^{66}$. Asimismo, resulta sintomático de lo que explicamos que los ecijanos, cuya caballería sí jugó un papel destacado en la entrada del marqués de Mondéjar en las Alpujarras durante el primer trimestre de $1569^{67}$, registren 11 de los 46 moriscos $(23,9 \%)$ correspondientes a la actual provincia de Sevilla; su activa participación durante toda la guerra en los principales hechos de armas propició el traslado a Écija de cientos de esclavos moriscos, que, en 1573 alcanzaban la cifra de 476,

${ }^{62}$ Como Hernando de Tapia, vecino de Órgiva, que registró dos moriscas en su pueblo el día 7 de febrero de 1569, y otras ocho el día 13 de marzo (AGS: CMC-I, leg. 1913, doc. 6. Relación). Era alguacil del juzgado de Ugíjar, según sabemos por otro documento anterior, y Mármol lo llama «cuadrillero de los que andaban en seguimiento de los monfíes» en los tiempos previos a la guerra, participando, lógicamente, en la misma (Mármol, Historia, p. 189, véase también la nota 39, con más información sobre su historial delictivo); similar es el caso de Juan López, vecino de Béznar según la Relación, que registra cinco moriscas y dos moriscos en marzo de 1569, al que Mármol califica de «animoso soldado, natural de Órgiva», «muy ladino» en la lengua árabe (Mármol, Historia, p. 325).

${ }^{63}$ Fernández Chaves y Pérez García, En los márgenes de la Ciudad de Dios, pp. 122125; Pérez García, "Moriscos en Antequera”, pp. 95-100; Pérez García y Fernández Chaves, "La guerra de Granada entre guerra civil y «guerra justa»", pp. 229-247. 88.

${ }^{64}$ Fernández Chaves y Pérez García, En los márgenes de la Ciudad de Dios, pp. 83-

${ }^{65}$ Ese día, el mercader sevillano Luis de la Peña vendió a una esclava morisca blanca llamada Isabel, de 20 años, que había sido herrada «en la barba» (Archivo Histórico Provincial de Sevilla [en adelante AHPSe]: Protocolos Notariales de Sevilla [en adelante PNS], leg. 7761).

${ }^{66}$ Fernández Chaves y Pérez García, En los márgenes de la Ciudad de Dios, p. 93.

${ }^{67}$ De hecho, las compañías de Écija estuvieron con el ejército de Mondéjar en Ugíjar y en la toma de Las Guájaras (Sanz Fuentes, “Contribución de la ciudad de Écija”, p. 988). 
muchos de ellos del valle de Lecrín y de las tahas de Órgiva, Jubiles, Ugíjar y otras de las Alpujarras ${ }^{68}$.

El hecho de que durante los meses estudiados en este trabajo la situación de los moriscos apresados fuera el depósito, a la espera del dictamen acerca de su libertad o esclavitud, no impidió en absoluto a sus captores hacer negocio con ellos, transmitiéndolos a cambio de dinero en operaciones que no eran sino ventas encubiertas. Nos avisa de ello la fórmula, recogida en tantas cartas de compraventa, de que la validez de éstas quedaba supeditada a las pendientes resoluciones al respecto del rey, la Inquisición o el papa ${ }^{69}$. Es precisamente esta circunstancia la que nos permite acercarnos al inicial proceso de distribución de los moriscos esclavizados desde el reino de Granada hacia la Andalucía del Guadalquivir. El estudio de algunos ejemplos relativos a vecinos de Antequera o Sevilla resulta muy aclarador.

El caso de Juan Díaz, un calcetero de Antequera que el 3 de febrero de 1569 registró en Ugíjar de las Alpujarras a una morisca llamada Isabel acompañada de su hija ${ }^{70}$, es ilustrativo del funcionamiento coyuntural del reino de Granada como un gigantesco mercado de esclavos entre 1569 y 1571 . Poco después, el 19 de marzo, el mismo Juan Díaz se encontraba ya en Antequera, donde explicaba que hacía un mes y medio había estado «en el real del marqués de Mondéjar» y que en el lugar de Ugíjar hubo «despojo por prisionera» de una morisca llamada Isabel de Carvajal y a una niña hija de ésta, de año y medio, llamada María; Díaz dijo que cuando quiso sacarla de allí se obligó ante escribano a devolverla si el rey así lo ordenaba, constituyéndose entre tanto en depositario de la misma. No obstante, aquel mismo día traspasó dicha depositaría, mediante una operación de venta encubierta, a Juan Domínguez, un zapatero de Utrera, tras recibir de él 26.928 maravedís como pago $^{71}$. No se trataba de un hecho aislado, en absoluto. Durante los mismos días, otros antequeranos que regresaban después de haber servido en el ejército de Mondéjar realizaron idénticas transacciones.

\footnotetext{
${ }^{68}$ Fernández Chaves y Pérez García, "Notas sobre la destrucción de las comunidades moriscas malagueñas", pp. 121-139.

${ }^{69}$ Fernández Chaves y Pérez García, En los márgenes de la Ciudad de Dios, pp. 120121.

${ }^{70}$ AGS: CMC-I, leg. 1913, doc. 6. Relación...

${ }^{71}$ Archivo Histórico Municipal de Antequera (en adelante AHMA): Fondo Notarial (en adelante FN), leg. 1122, f. 81. Antequera, 19-III-1569.
} 
Julián de Molina, procurador de Antequera, que el 4 de febrero registró en Ugíjar a una morisca llamada Isabel ${ }^{72}$, también la traspasó en su ciudad a Alonso de Salamanca, un ropero vecino de Sevilla por precio de 24.000 maravedís, especificando que era depositario de la misma y que ésta tenía 24 años $^{73}$. Otro vecino de Antequera, el clérigo presbítero Alonso Villalón, que el 31 de enero registró en Ugíjar a un morisco llamado Bartolomé ${ }^{74}$, hizo la misma operación: su caso nos avisa de la agilidad de este mercado de esclavos, pues solo tres días más tarde, y como depositario del mismo, se encontraba en Antequera, donde lo traspasó por 8.976 maravedís al curtidor Francisco Hernández, también vecino de Utrera; el precio menor se debe a que Bartolomé solo tenía 8 años de edad ${ }^{75}$. Gabriel de Treviñón, alguacil mayor de Antequera, que había comandado junto con el corregidor de la misma a las tropas de la ciudad que se unieron al ejercito del marqués de Mondéjar ${ }^{76}$, también estuvo en la toma de Jubiles el 18 de enero, donde obtuvo como «despojo» y «prisionera» a una morisca llamada María de 34 años y a su hija Luisa de 10 meses; allí se constituyó como depositario de las mismas y posteriormente, el 3 de marzo de aquel año, en Antequera, las traspasó mediante la correspondiente venta encubierta a Antón Pacheco, labrador de Utrera, por precio de 18.375 maravedís y con la consabida condición de que si el rey, la Inquisición o el papa las declaraban libres, la compraventa sería anulada y habría de devolver el importe de la misma ${ }^{77}$. Este mismo Antón Pacheco compró (no sabemos dónde), tres meses más tarde, el 12 de junio, a Benito de Aranda, zapatero de Granada, una esclava morisca de 18 años llamada María, natural de Nigüelas (en el valle de Lecrín) y que había sido cautivada en Las Albuñuelas; el 30 de septiembre la vendía en Utrera por 30.750 maravedís $^{78}$. Es in-

${ }^{72}$ AGS: CMC-I, leg. 1913, doc. 6. Relación...

${ }^{73}$ AHMA: FN, leg. 1122, f. 83. Antequera, 21-III-1569. También afirma Molina que estuvo en el real y ejército del marqués de Mondéjar.

${ }^{74}$ AGS: CMC-I, leg. 1913, doc. 6. Relación...

${ }^{75}$ AHMA: FN, leg. 1122, f. 132. Antequera, 3-II-1569. Es en este documento donde consta la condición eclesiástica de Villalón, el cual afirma aquí que la escritura de depositario la hizo estando en el real de Su Majestad en el Hondón de Andarax con el marqués de Mondéjar.

${ }^{76}$ Mármol, Historia, libro V, cap. I.

${ }^{77}$ AHMA: FN, leg. 1122, f. 79. Antequera, 3-III-1569.

${ }^{78}$ AHPSe: Protocolos Notariales de Utrera, leg. 22434P. Agradezco a Elena Lobo Guerrero haberme facilitado este dato fruto de su investigación. 
teresante el hecho de que sean precisamente vecinos de Utrera y Sevilla los que adquieren esos moriscos en Antequera entre febrero y marzo de 1569, actuando así de transmisores de la mercancía humana hacia sus localidades de origen. De hecho, algunos de ellos se trasladaron no solo hasta Antequera en busca de moriscos esclavizados, sino hasta la misma Alpujarra: así, Pedro Jiménez, vecino de Utrera, registró en Ugíjar el día 1 de febrero de 1569 un grupo de 12 moriscos ( 8 de sexo femenino y 4 masculino), en el que no faltaban dos mujeres con sus hijos $^{79}$. El alza brutal del número de moriscos vendidos en Sevilla desde los últimos días de febrero y durante el mes de marzo de $1569^{80}$ tiene que ver precisamente con este fenómeno de intermediación, dado que sus tropas todavía no se habían dirigido al escenario bélico.

Esta cadena de sucesivas transmisiones que permitía la exportación de los moriscos esclavizados, se sostenía por un claro incremento del precio de éstos cuando se encontraban fuera del reino de Granada. Mármol ya avisaba, como vimos, de que el precio de los esclavos moriscos en las zonas de captura era irrisorio, y así lo confirman para otros escenarios y momentos de la guerra los datos aportados al respecto por Manuel F. Fernández Chaves ${ }^{81}$. Los precios que se pagaban en Antequera eran considerables, de hecho eran prácticamente homologables a los de Sevilla ${ }^{82}$ o Córdoba ${ }^{83}$ en las mismas fechas, aunque sensiblemente superiores a los abonados en la ciudad de Granada ${ }^{84}$, donde a su vez eran mayores que en la Alpujarra. Ello muestra el carácter regional (andaluz) del mercado de esclavos en lo referente a mercancía y precios, y que la revalorización del precio del esclavo morisco era especialmente notable cuando se le sacaba fuera de las fronteras del reino de Granada, donde se reducían las posibilidades de fuga ${ }^{85}$ y se amplia-

${ }^{79}$ AGS: CMC-I, leg. 1913, doc. 6. Relación... 93-94.

${ }^{80}$ Fernández Chaves y Pérez García, En los márgenes de la Ciudad de Dios, pp.

${ }^{81}$ Fernández Chaves, "En las postrimerías de la guerra de la Alpujarra: cabalgadas y esclavización de los moriscos en 1571".

${ }^{82}$ Vid infra.

${ }^{83}$ Aranda Doncel Los moriscos en tierras de Córdoba, p. 150.

${ }^{84}$ Martín Casares, La esclavitud en la Granada del siglo XVI, pp. 224-233.

${ }^{85} \mathrm{La}$ fuga fue una constante durante los años de la guerra y los siguientes, especialmente entre aquellos que se encontraban cerca de la frontera del reino de Granada, algo que además preocupaba a las autoridades (véase, por ejemplo, Pérez García, "Moriscos en Antequera”, pp. 78-79). 
ban las posibilidades de venta. La redistribución desde las localidades de frontera, como Antequera, hacia el valle del Guadalquivir y ciudades como Sevilla, Écija o Córdoba, respondía, pues, ante todo, a la necesidad de buscar demanda para tal masa de esclavos; de igual modo las numerosas ventas llevadas a cabo por jiennenses en Córdoba, donde sin duda encontraban mayores oportunidades de venta y mejores precios para sus esclavos moriscos que en el reino de Jaén ${ }^{86}$. Fueron cuestiones tanto logísticas (la dificultad de la gestión y transporte de cientos o miles de individuos esclavizados) como de demanda (incrementar aún más la avalancha hacia ciudades como Sevilla podría haber afectado negativamente a los precios de venta) las que produjeron acumulaciones durante meses, o incluso años (hasta 1573 básicamente), de un enorme número de moriscos esclavizados en las ciudades próximas a la frontera granadina, como Alcalá la Real ${ }^{87}$, Antequera ${ }^{88}$ o Écija ${ }^{89}$, o del propio reino de Granada, como Guadix ${ }^{90}$.

En ocasiones, no obstante, la acumulación de esclavos moriscos en las ciudades de la frontera tenía también que ver con el deseo de sus propietarios de conservarlos y valerse ellos mismos de su trabajo. Así, un miembro de una de las más preclaras y poderosas familias de la oligarquía nobiliaria de Antequera ${ }^{91}$, Hernán Chacón, cuando estuvo en la toma del fuerte de Jubiles el 18 de enero de 1569, capturó (junto con un tal Juan Enríquez) a un morisco llamado Íñigo, de unos trece años de edad, comprando luego a Enríquez, ya en Antequera, y en septiembre de aquel año, su parte de derecho sobre el mismo por 4.500 maravedís ${ }^{92}$. Cuatro años más tarde, en 1573, Hernán Chacón todavía conservaba a aquel morisco, del que se decía que era ya un «mozo» de 16 años: el Registro de moriscos de Antequera nos confirma que, aunque originario de Dúrcal, había sido capturado en el castillo de Jubiles,

${ }^{86}$ Aranda Doncel, Los moriscos en tierras de Córdoba, p. 148.

${ }^{87}$ San Martín Vadillo, "Esclavos de Alcalá en tiempos de Carlos V”, pp. 359-369.

${ }^{88}$ Pérez García, "Moriscos en Antequera”, pp. 75-110.

${ }^{89}$ Vid supra.

${ }^{90}$ Garrido García, La esclavitud en el reino de Granada, pp. 278-289, 449-450, 453455; Garrido García, "La esclavitud de los moriscos capturados" y Garrido García, "La expulsión de los moriscos del reino de Granada de 1584. El caso de Guadix y su tierra".

${ }^{91}$ Era hijo de Juan Chacón y su esposa doña Inés de Rojas (AHMA: FN, leg. 1122, f. 419), y su hermano era don Alonso de Rojas (AHMA: Fondo Municipal [en adelante FM], leg. 3298. Registro de moriscos en Antequera, 1573).

${ }^{92}$ AHMA: FN, leg. 1122, f. 419. Antequera, 9-IX-1569. 
donde fue marcado con un clavo entre las cejas. En ese mismo año, Chacón registró, a través de su hermano don Alonso de Rojas, a otro esclavo morisco llamado Pedro, de Trevélez, de 14 años, también capturado en Jubiles y marcado de la misma manera, y a Isabel, de 30 años y oriunda de Notáez, cerca de Jubiles, donde también fue capturada. En al menos los dos primeros casos, Rojas, en representación de su hermano, protestó ante el alcalde mayor de Antequera por el hecho de tener que «exhibir» a sus esclavos, posiblemente para reforzar y recordar el derecho de guerra que le amparaba en dicha posesión ${ }^{93}$.

Así, vemos que todavía en 1573 se encontraban en Antequera numerosas moriscas de las capturadas en las Alpujarras durante el primer trimestre de 1569. En el Registro de moriscos presentes en Antequera elaborado durante el verano de 1573, quedó constancia de la presencia en la ciudad de 843 hombres y mujeres, de los que 169 procedían de las Alpujarras granadinas y 43 del valle de Lecrín. Y la mayoría de aquellos eran oriundos de las tahas más afectadas por la entrada del marqués de Mondéjar: 27 de la de Órgiva, 10 de la de Poqueira, 18 de la de Ferreira, 66 de la de Jubiles y 29 de la de Ugíjar ${ }^{94}$. Evidentemente no todos habían sido esclavizados durante aquellos primeros meses de la guerra, pero, afortunadamente para nosotros, el Registro de moriscos de Antequera de 1573 nos informa a menudo de las circunstancias del cautiverio de cada individuo, lo que nos permite detectar cómo todavía a mediados de 1573 un buen número de los moriscos capturados durante la campaña de Mondéjar se encontraban allí. Agustín, un muchacho morisco de once años natural de Molvízar, declaró que «lo capturaron al principio de la guerra en las Alpujarras», igual que Isabel (apresada con su bebé), natural de Ugíjar y cautivada cerca de allí. Casi una treintena de moriscos de los estantes en Antequera en el verano de 1573 habían sido capturados en Jubiles, y muchos habían vivido en primera persona los terribles sucesos acaecidos allí durante la noche del 18 al 19 de enero de 1569: Sabina, de 20 años y natural de Cónchar (en el valle de Lecrín), explicaba que «la cautivaron en Jubiles, víspera del señor Sevastián al principio de la guerra»; Isabel, de Pitres de Ferreira y con treinta años, declaró que «la captivaron en Jubiles a la

${ }^{93}$ AHMA: FM, leg. 3298. Registro de moriscos en Antequera, 1573.

${ }^{94}$ Pérez García, "Moriscos en Antequera", pp. 81-82, 89; y AHMA: FM, leg. 3298. Registro de moriscos en Antequera, 1573. 
puerta de la iglesia, víspera del señor San Sebastián»; Luisa, de Cástaras, y Sabina, de Melegís en el valle de Lecrín, ambas de 40 años, afirmaron que las cautivaron «la noche de Jubiles»; María Magroça, de Mondújar (también en el valle de Lecrín), María, de Órgiva, y Lucía, de Bargis, fueron cautivadas en la iglesia de Jubiles, y otra María, de Trevélez, fue apresada a las puertas de la misma; Inés, de Ferreira y con 16 años en 1573, también contó que la cautivaron en la iglesia de Jubiles y puntualizó que eso fue «al principio del primer levantamiento»; en ocasiones indicaron que fueron capturados en el «fuerte» o «castillo» de Jubiles, como Bernardino, de Vélez, o Íñigo, de Dúrcal, ambos con 16 años en 1573, o Isabel, de Pitres de Ferreira, que tendría solo 7 u 8 años cuanto fue cautivada ${ }^{95}$. Estas historias confirman la validez del relato de Mármol y muchos de sus detalles, y nos recuerdan cómo los moriscos de muy diversas partes del valle de Lecrín y de las tahas alpujarreñas cercanas habían reunido en el fuerte de Jubiles a sus mujeres y niños. Ese fue el punto de captura masiva, y Antequera una de las primeras estaciones en su proceso de comercialización como esclavos. Desde aquí muchos continuaron camino hacia los grandes núcleos urbanos del valle del Guadalquivir, donde se radicaba la principal demanda de mano de obra esclava.

En Sevilla también se documenta la venta de esclavos moriscos de las Alpujarras capturados durante la campaña de Mondéjar, al menos desde febrero de $1569^{96}$, acentuándose el fenómeno a partir del mes siguiente. Así, el 27 de febrero de 1569 se vendía en Sevilla a un niño morisco de las Alpujarras de Granada de 6 ó 7 años llamado Juan por 12.750 maravedís $^{97}$. El 21 de marzo era el turno de Cecilia, morisca de 34 años, vendida junto a su hija Isabel de 2 añitos, que «fueron captivas en el reino de Granada en las Alpujarras del dicho reino»: pagaron por ellas 30.000 maravedís, y se avisó al comprador de que si el rey o el papa declaraban que eran libres y no esclavas, la operación no tendría validez ${ }^{98}$, dato que nos recuerda los procedimientos que vimos utilizar

${ }^{95}$ AHMA: FM, leg. 3298. Registro de moriscos en Antequera, 1573.

${ }^{96}$ El hecho de que, en la mayoría de las ocasiones, las cartas de venta de esclavos moriscos del reino de Granada realizadas en Sevilla no indiquen el lugar de origen de éstos, nos impide retrotraer la cronología de este proceso al mes de enero, algo que es bien plausible.

${ }^{97}$ AHPSe: PNS, leg. 118, f. 667v-668v.

${ }^{98}$ AHPSe: PNS, leg. 1085, f. 489v-490v. 
en Antequera por las mismas fechas. La niña Isabel, de Ferreira, de 8 años, fue vendida en Sevilla el 28 de marzo por 16.500 maravedís $^{99}$, y dos días más tarde fue el turno de María, también de Ferreira y con 13 años, por la que se abonaron 18.750 maravedís, y también a devolver si se produjese una declaración del rey a favor de su libertad ${ }^{100}$. El 6 de abril vendieron a un «esclavito morisco que es de los que se alzaron en el reino de Granada, natural de Ujígar», de 8 años, por 13.875 maravedís ${ }^{101}$; otro niño de Ugíjar, Luis, de la misma edad y «aljamiado», fue vendido el 8 de mayo por 11.250 maravedís y avisándose de que el dinero sería devuelto si las autoridades declaraban su libertad ${ }^{102}$. La brutalidad de aquellas situaciones se percibe todavía más en la venta, el 12 de junio de 1569, de la morisca Cecilia, de 30 años, también de las Alpujarras, vendida junto con su hijo Alonso, de solo un año de edad, «que está el niño enfermo, muriéndose»: por ellos pagaron 18.750 maravedís al contado ${ }^{103}$.

En ocasiones, las cartas de compraventa nos explican con precisión cómo llegaron los esclavos desde las Alpujarras hasta Sevilla: es un proceso que ya vamos conociendo, bien directamente gracias a los propios captores, bien mediante el sistema de compras sucesivas. E1 23 de abril de 1569, Diego Martínez de Córdoba, contador y vecino de Córdoba vendió en Sevilla a la morisca blanca Cecilia, de 23 años, del peñón de Las Guájaras Bajas, por 28.125 maravedís, declarando «abella abido y catibado en el peñón de las dichas Guájaras y de las que el marqués de Mondéjar hizo [...] y repartió a los capitanes de caballo quando se conquistó el dicho peñón ${ }^{104}$. Una semana antes, el 16 de abril, Juan de Vargas, un cestero sevillano, vendía en Sevilla a una morisca natural de las Alpujarras que previamente había comprado en Granada el día 6 de marzo a un tal Alonso de Aguilar, vecino de Alcalá de Henares: por la venta en Sevilla de Cecilia, de 30 años, obtuvo 24.375 maravedís ${ }^{105}$.

\footnotetext{
${ }^{99}$ AHPSe: PNS, leg. 118, f. 920v-921v.

${ }^{100}$ AHPSe: PNS, leg. 118, f. 947r-948r.

${ }^{101}$ AHPSe, PNS, leg. 4060, f. 1614r-1615v.

${ }^{102}$ AHPSe: PNS, leg. 16684, f. 60r-v.

${ }^{103}$ AHPSe: PNS, leg. 16034, f. 916r-v.

${ }^{104}$ AHPSe: PNS, leg. 7762, f. 62r-63v.

${ }^{105}$ AHPSe: PNS, leg. 16034, f. 194r-v.
} 
Los comandantes de las tropas y especialmente los capitanes de las compañías de infantería y caballería también jugaron un papel crucial en la saca del reino de Granada de una porción importante de los moriscos esclavizados. Ya hemos visto algunos casos. Se trata de algo fácil de comprender dado que solían ser beneficiarios de partes importantes del botín de guerra. Hemos podido identificar a 26 capitanes que sirvieron en el ejército de Mondéjar y que quedaron recogidos en la $R e$ lación registrando un total de 130 esclavos (Anexo: Tabla 5), el 10,1\% del total; si a éstos sumamos otros 80 moriscos registrados por otros oficiales, corregidores, regidores y nobles destacados (Anexo: Tabla 6), el total representado por todos estos alcanzaría el 16,3\%, tratándose, no obstante, de un cálculo a la baja debido a la dificultad de identificar a muchos de los registradores de la Relación y que, sin duda, también pertenecían a estos grupos. A partir de aquí, encontramos a toda la escala del ejército registrando esclavos: tres sargentos, siete alféreces (de compañías de Martos, Úbeda, Baeza, Granada y otras, que registran 19 moriscos), artilleros, alabarderos y, por supuesto, muchos soldados... Porque, durante 1569-1571, el reino de Granada funcionó coyunturalmente como un gigantesco mercado de esclavos donde miles de sus habitantes moriscos fueron capturados, esclavizados y vendidos fuera del mismo: en ello participaron los militares, también los traficantes profesionales de esclavos, pero, sobre todo, fueron cientos, miles de personas insignificantes y anónimas las que hicieron posible tal y tan gran negocio. 


\section{Anexo}

Tabla 4

Vecindad de las personas que registran moriscos en las Alpujarras según la Relación (enero a abril de 1569)

\begin{tabular}{|c|c|c|}
\hline Territorio & $\begin{array}{l}\text { Número de moriscos } \\
\text { registrados }\end{array}$ & $\%$ \\
\hline \multicolumn{3}{|c|}{ 1. PROVINCIA DE GRANADA } \\
\hline Granada & 388 & 30,17 \\
\hline Motril & 55 & 4,28 \\
\hline Loja & 26 & 2,02 \\
\hline Alhama & 16 & 1,24 \\
\hline Órgiva & 14 & 1,08 \\
\hline Montefrío & 12 & 0,93 \\
\hline Albolote & 4 & 0,31 \\
\hline Íllora & 4 & 0,31 \\
\hline Víznar & 4 & 0,31 \\
\hline Montejícar & 3 & 0,23 \\
\hline Almuñécar & 3 & 0,23 \\
\hline Béznar & 3 & 0,23 \\
\hline Santa Fe & 2 & 0,15 \\
\hline Pinos & 2 & 0,15 \\
\hline Las Gabias & 2 & 0,15 \\
\hline Guadahortuna & 2 & 0,15 \\
\hline Ugíjar de la Vega & 1 & 0,075 \\
\hline Beas & 1 & 0,075 \\
\hline Total Prov. Granada & 542 & 42,15 \\
\hline \multicolumn{3}{|c|}{ 2. PROVINCIA DE MÁLAGA } \\
\hline Antequera & 96 & 7,46 \\
\hline Vélez-Málaga & 39 & 3,03 \\
\hline Archidona & 14 & 1,08 \\
\hline Málaga & 14 & 1,08 \\
\hline Ronda & 10 & 0,78 \\
\hline Marbella & 6 & 0,47 \\
\hline Total Prov. Málaga & 179 & 13,92 \\
\hline
\end{tabular}

Al-Qantara XLI 1, 2020, pp. 183-218 ISSN 0211-3589 doi: https//doi.org/10.3989/alqantara.2020.006 


\begin{tabular}{|c|c|c|}
\hline Territorio & $\begin{array}{l}\text { Número de moriscos } \\
\text { registrados }\end{array}$ & $\%$ \\
\hline \multicolumn{3}{|c|}{ 3. PROVINCIA DE ALMERÍA } \\
\hline Vera & 7 & 0,54 \\
\hline Paterna [del Río] & 2 & 0,15 \\
\hline Almería & 1 & 0,075 \\
\hline Total Prov. de Almería & 10 & 0,78 \\
\hline \multicolumn{3}{|l|}{ 4. PROVINCIA DE JAÉN } \\
\hline Baeza & 61 & 4,734 \\
\hline Úbeda & $44+10^{106}$ & 4,2 \\
\hline Baeza \& Úbeda & 4 & 0,31 \\
\hline Jaén & 26 & 2,02 \\
\hline Alcalá la Real & 23 & 1,8 \\
\hline Martos & 22 & 1,71 \\
\hline Alcaudete & 11 & 0,85 \\
\hline Quesada & 7 & 0,54 \\
\hline Porcuna & 7 & 0,54 \\
\hline Cazorla & 3 & 0,23 \\
\hline Bailén & 2 & 0,15 \\
\hline Vilches & 2 & 0,15 \\
\hline Pegalajar & 2 & 0,15 \\
\hline Linares & 1 & 0,075 \\
\hline Villanueva del Arzobispo & 1 & 0,075 \\
\hline Santisteban & 1 & 0,075 \\
\hline El Castellar & 1 & 0,075 \\
\hline Begíjar & 1 & 0,075 \\
\hline Total Prov. Jaén & 229 & 17 \\
\hline \multicolumn{3}{|c|}{ 5. PROVINCIA DE CÓRDOBA } \\
\hline Córdoba & 67 & 5,2 \\
\hline Iznájar & 8 & 0,62 \\
\hline Lucena & 8 & 0,62 \\
\hline Priego & 7 & 0,54 \\
\hline Baena & 2 & 0,15 \\
\hline Palma & 2 & 0,15 \\
\hline Bujalance & 1 & 0,075 \\
\hline Cabra & 1 & 0,075 \\
\hline Aguilar & 1 & 0,075 \\
\hline Rute & 1 & 0,075 \\
\hline Torremilano & 1 & 0,075 \\
\hline Total Prov. Córdoba & 99 & 7,7 \\
\hline
\end{tabular}

${ }^{106}$ Estos diez probablemente corresponden también a vecinos de Úbeda. 


\begin{tabular}{|c|c|c|}
\hline Territorio & $\begin{array}{l}\text { Número de moriscos } \\
\text { registrados }\end{array}$ & $\%$ \\
\hline \multicolumn{3}{|c|}{ 6. PROVINCIA DE SEVILLA } \\
\hline Utrera & 13 & 1,01 \\
\hline Écija & 11 & 0,85 \\
\hline Sevilla & 7 & 0,54 \\
\hline Morón de la Frontera & 4 & 0,31 \\
\hline El Arahal & 3 & 0,23 \\
\hline Marchena & 2 & 0,15 \\
\hline Estepa & 2 & 0,15 \\
\hline Osuna & 2 & 0,15 \\
\hline Carmona & 1 & 0,075 \\
\hline Villanueva del Río & 1 & 0,075 \\
\hline Total Prov. Sevilla & 46 & 3,6 \\
\hline \multicolumn{3}{|c|}{ 7. PROVINCIA DE CÁDIZ } \\
\hline Gibraltar & 1 & 0,075 \\
\hline Total Prov. Cádiz & 1 & $\mathbf{0 , 0 7 5}$ \\
\hline \multicolumn{3}{|c|}{ 8. PROVINCIA DE MURCIA } \\
\hline Pliego & 4 & 0,31 \\
\hline Lorca & 2 & 0,15 \\
\hline Total Prov. Murcia & 6 & 0,46 \\
\hline \multicolumn{3}{|l|}{ 9. SUBMESETA SUR } \\
\hline Madrid & 4 & 0,31 \\
\hline Alcaraz & 4 & 0,31 \\
\hline Toledo & 3 & 0,23 \\
\hline Belmonte & 3 & 0,23 \\
\hline Valdelagua & 2 & 0,15 \\
\hline Villanueva de los Infantes & 2 & 0,15 \\
\hline Alcalá de Henares & 1 & 0,075 \\
\hline Valdepeñas & 1 & 0,075 \\
\hline San Clemente & 1 & 0,075 \\
\hline Meco & 1 & 0,075 \\
\hline Torijos & 1 & 0,075 \\
\hline Los Yébenes & 1 & 0,075 \\
\hline Total Submeseta Sur & 24 & 1,87 \\
\hline
\end{tabular}

Al-Qantara XLI 1, 2020, pp. 183-218 ISSN 0211-3589 doi: https//doi.org/10.3989/alqantara.2020.006 


\begin{tabular}{|l|c|c|}
\hline \multicolumn{1}{|c|}{ Territorio } & $\begin{array}{c}\text { Número de moriscos } \\
\text { registrados }\end{array}$ & $\%$ \\
\hline 10. SUBMESETA NORTE & 3 & 0,23 \\
\hline Valladolid & 2 & 0,15 \\
\hline Huérmeces [Burgos] & 1 & 0,075 \\
\hline Griñón (tierras de La Rioja) & 1 & 0,075 \\
\hline Burgos & 1 & 0,075 \\
\hline Salamanca & 1 & 0,075 \\
\hline Soria & $\mathbf{9}$ & 0,7 \\
\hline Total Submeseta norte & 99 & 7,69 \\
\hline 11. SIN IDENTIFICACIÓN / OTROS & 1,24 \\
\hline Sin identificación de vecindad & 16 & 0,7 \\
\hline Granada \& Úbeda & 9 & 0,85 \\
\hline Granada \& Madrid & 11 & 0,075 \\
\hline Alcalá (sin especificar) & 1 & 0,23 \\
\hline Marsella & 3 & 0,15 \\
\hline Tovara & 2 & $\mathbf{1 1}$ \\
\hline La Parra & $\mathbf{1 4 1}$ & $\mathbf{1 0 0}$ \\
\hline Total Sin identificación & $\mathbf{1 . 2 8 6}$ & \\
/ Otros & & \\
\hline TOTAL & 9 & \\
\hline
\end{tabular}


Tabla 5

Capitanes del ejército del marqués de Mondéjar que registran moriscos en las Alpujarras según la Relación (enero a abril de 1569) ${ }^{107}$

\begin{tabular}{|c|c|c|c|}
\hline Nombre & Cargo & Vecindad & $\begin{array}{c}\text { Número } \\
\text { de moriscos } \\
\text { que registra }\end{array}$ \\
\hline D. Francisco de Simancas & capitán & Córdoba & 7 \\
\hline Cosme de Armenta ${ }^{108}$ & capitán & Córdoba & 14 \\
\hline Pedro de Covaleda & capitán & Jaén & 2 \\
\hline Bartolomé de Aranda & capitán & Jaén & 4 \\
\hline Miguel Jerónimo de Mendoza ${ }^{109}$ & capitán & Jaén & 1 \\
\hline Juan Alonso de Santiago & capitán & Martos & 2 \\
\hline D. Rodrigo de Vivero & $\begin{array}{c}\text { corregidor de Úbeda } \\
\text { y Baeza }^{110}\end{array}$ & Úbeda \& Baeza & 4 \\
\hline Antonio de Flores Benavides & $\begin{array}{c}\text { capitán de la infantería } \\
\text { de Baeza }\end{array}$ & Baeza & 16 \\
\hline Juan Ochoa de Navarrete & $\begin{array}{c}\text { capitán de la infantería } \\
\text { de Baeza }{ }^{111}\end{array}$ & [Baeza] & 5 \\
\hline Gonzalo Chacón & $\begin{array}{c}\text { capitán de la compañía } \\
\text { de Baeza }\end{array}$ & - & 2 \\
\hline Juan de Carvajal & $\begin{array}{c}\text { capitán de la compañía } \\
\text { de Baeza }\end{array}$ & Baeza & 2 \\
\hline Baltasar de Aranda & capitán & Baeza & 7 \\
\hline Don Antonio Porcel & 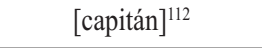 & Úbeda & 2 \\
\hline Don García [Fernández] Manrique & capitán & Úbeda & 2 \\
\hline $\begin{array}{l}\text { Maldonado / } \\
\text { D. García Manrique }\end{array}$ & capitanes & Granada / Úbeda & 16 \\
\hline Alonso de Robles & capitán & Úbeda & 4 \\
\hline
\end{tabular}

${ }^{107}$ Incluimos entre corchetes datos no aportados por la Relación pero conocidos gracias a otras fuentes.

${ }^{108}$ Sobre este, Mármol, Historia, p. 379.

${ }^{109}$ Véase Mármol, Historia, p. 377.

${ }^{110}$ Dirigía las tropas de Úbeda y Baeza cuando éstas se unieron al ejército del marqués de Mondéjar (Mármol, Historia, libro V, cap. IV, p. 310); también se encontró en la toma de Jubiles (Mármol, Historia, libro V, cap. XX, p. 345).

${ }^{111}$ Mármol, Historia, p. 339.

112 Dice Mármol que «la infantería de Úbeda gobernaban don Antonio Porcel, don Garci Fernández Manrique y Francisco de Molina» (Mármol, Historia, libro V, cap. IV, p. $310)$. 


\begin{tabular}{|c|c|c|c|}
\hline Nombre & Cargo & Vecindad & $\begin{array}{c}\text { Número } \\
\text { de moriscos } \\
\text { que registra }\end{array}$ \\
\hline [Lorenzo de] Leiva ${ }^{113}$ & capitán & Úbeda & 1 \\
\hline Gonzalo de Alcántara $^{114}$ & capitán & Vélez-Málaga & 6 \\
\hline [D.] Anton[io] Pérez & $\begin{array}{l}\text { regidor [capitán } \\
\text { de infantería] }\end{array}$ & Vélez-Málaga & 2 \\
\hline D. Diego de Rojas Narváez & capitán & Antequera & 8 \\
\hline D. Diego de Narváez & $\begin{array}{c}\text { comendador } \\
{[\text { manda infantería }} \\
\text { de Antequera] }{ }^{116}\end{array}$ & Antequera & 4 \\
\hline Íñigo Delgado [de San Vicente] ${ }^{117}$ & $\begin{array}{l}\text { [capitán de } \\
\text { infantería] }{ }^{118}\end{array}$ & Archidona & 6 \\
\hline Lázaro Moreno de León & [capitán] $^{119}$ & Granada & 1 \\
\hline D. Luis de la Cueva & {$\left[\right.$ capitán] ${ }^{120}$} & Granada & 8 \\
\hline Juan de Luján & capitán & Madrid & 2 \\
\hline Rodrigo de Álava & capitán & $\begin{array}{l}\text { Huérmeces } \\
\text { (Burgos) }\end{array}$ & 2 \\
\hline
\end{tabular}

${ }^{113}$ Nota biográfica en Mármol, Historia, p. 529, nota 180.

${ }^{114}$ Véase Mármol, Historia, p. 282.

${ }^{115}$ Mármol, Historia, libro VI, cap. XXIII, p. 463.

${ }^{116}$ Mármol, Historia, libro V, cap. XXXI, p. 377. toria.

${ }^{117}$ Este capitán hizo prácticamente toda la guerra, numerosos datos en Mármol, His-

${ }^{118}$ Mármol, Historia, libro X, cap. II, p. 707.

${ }^{119}$ Según Mármol, en 1570 era «capitán de arcabuceros de a caballo y vecino de Granada», participando activamente en la guerra (Mármol, Historia, libro VIII, cap. XVIII, p. 633; más datos en pp. 648 y 707).

${ }^{120}$ Nota biográfica sobre este en Mármol, Historia, p. 529, nota 181. 
Tabla 6

Cargos públicos, nobles y notables que registran moriscos en las Alpujarras según la Relación (enero a abril de 1569)

\begin{tabular}{|c|c|c|c|}
\hline Nombre & Identificador & Vecindad & $\begin{array}{l}\text { Número } \\
\text { de moriscos } \\
\text { que registra }\end{array}$ \\
\hline Ldo. Diego Méndez & $\begin{array}{l}\text { corregidor } \\
\text { de Archidona }\end{array}$ & Archidona & 1 \\
\hline D. Pedro de Narváez & - & Antequera & 5 \\
\hline Ruy Díaz de Rojas & comendador & Antequera & 5 \\
\hline D. Juan de Mancha & - & Antequera & 4 \\
\hline D. Pedro Fajardo & - & Écija & 5 \\
\hline $\begin{array}{l}\text { D. Martín }{ }^{121} \text { y D. Alonso de Ar- } \\
\text { gote, D. Antonio de las Infantas y } \\
\text { D. Alonso }\end{array}$ & - & Córdoba & 8 \\
\hline $\begin{array}{l}\text { Alonso, Pedro }{ }^{122} \text { y D. Antonio de } \\
\text { Velasco }\end{array}$ & - & Córdoba & 11 \\
\hline D. Hernando de Angulo & - & Córdoba & 2 \\
\hline D. Francisco de Santillán & Veinticuatro & Sevilla & 2 \\
\hline D. Alonso Vanegas & - & Granada & 4 \\
\hline D. Luis de Córdoba ${ }^{123}$ & $\begin{array}{l}\text { [alférez general del } \\
\text { reino de Granada] }\end{array}$ & Granada & 7 \\
\hline Juan Bautista Cataño & [genovés] ${ }^{125}$ & Granada & 4 \\
\hline D. Juan Velázquez Ronquillo & {$\left[\right.$ veedor] ${ }^{126}$} & - & 10 \\
\hline D. Jerónimo de Padilla ${ }^{127}$ & - & Madrid \& Granada & 7 \\
\hline Ldo. Carcelón & $\begin{array}{c}\text { Alcalde mayor } \\
\text { de la villa de Motril }\end{array}$ & Motril & 5 \\
\hline
\end{tabular}

${ }^{121}$ Noticia del mismo en Mármol, Historia, p. 667.

${ }^{122}$ Aparece en Mármol, Historia, pp. 633, 635.

${ }^{123}$ Véase Mármol, Historia, p. 636.

${ }^{124}$ Vincent, "Les jesuites chroniqueurs", p. 455.

${ }^{125}$ Cuenta Mármol que, en los primeros días de la guerra, los mercaderes genoveses de la ciudad de Granada hicieron una compañía propia, «que en armas y aderezos de sus personas hacía ventaja a las demás» (Mármol, Historia, libro IV, cap. XXXII). Como grupo han sido estudiados por extenso en Girón Pascual, Comercio y poder. Mercaderes genoveses en el sureste de Castilla durante los siglos XVI y XVII.

${ }^{126}$ Mármol, Historia, p. 375.

${ }^{127}$ Sin duda, juega un papel destacado en el ejército (Mármol, Historia, pp. 375-376, $396,552)$. 


\section{Fuentes de archivo}

Archivo General de Simancas:

- Contaduría Mayor de Cuentas - Primera Época, leg. 1913, doc. 6.

Archivo Histórico Municial de Antequera:

- Fondo Municipal: leg. 3298.

- Fondo Notarial: leg. 1122.

Archivo Histórico Provincial de Sevilla:

- Protocolos Notariales de Sevilla: legs. 118, 1085, 4060, 7761, 7762, 16034, 16684.

- Protocolos Notariales de Utrera: leg. 22434P.

\section{Bibliografía}

Aranda Doncel, Juan, Los moriscos en tierras de Córdoba, Córdoba, Publicaciones del Monte de Piedad y Caja de Ahorros de Córdoba, 1984.

Aranda Doncel, Juan, "Los esclavos en Jaén durante el último tercio del siglo XVI", en Homenaje a Antonio Domínguez Ortiz, Madrid, Ministerio de Educación y Ciencia, 1981, pp. 233-251.

Barrios Aguilera, Manuel, "El morisco como botín. Noticia sobre la presa de Inox en la guerra de Granada (1569)", en Antonio Luis Cortés Peña, Miguel Luis López-Guadalupe Muñoz y Francisco Sánchez-Montes (eds.), Estudios en homenaje al profesor José Szmolka Clares, Granada, Universidad de Granada, 2005, pp. 201-209.

Barrios Aguilera, Manuel, "La guerra de los moriscos de Granada en el Sumario de prohezas y casos de guerra de Juan de Arquellada", Chronica Nova, 22 (1995), pp. 407-428.

Benítez Sánchez-Blanco, Rafael, "El cautiverio de los moriscos", en Manuscrits, 28 (2010), pp. 19-43.

Cabrillana, Nicolás, Moriscos y cristianos en Yunquera, Málaga, Arguval, 1994.

Cabrillana, Nicolás, Almería morisca, $2^{\mathrm{a}}$ ed., Granada, Universidad de Granada, 1989.

Cabrillana, Nicolás, Marbella en el Siglo de Oro, Granada, Universidad de Granada \& Ayuntamiento de Marbella, 1989.

Cepeda Adán, José, "Los últimos Mendozas granadinos del siglo XVI”, en Miscelánea de estudios dedicados al profesor Marín Ocete, Granada, Universidad de Granada, 1974, I, pp. 183-204.

De la Obra Sierra, Juan María y Osorio Pérez, María José, "Los escribanos de las Alpujarras (1500-1568)", en María Amparo Moreno Trujillo, Juan María de la Obra Sierra y María José Osorio Pérez (coords.), El notariado andaluz: institución, práctica notarial y archivos. Siglo XVI, Granada, Universidad de Granada, 2011, pp. 89-126. 
Fernández Chaves, Manuel F., "En las postrimerías de la guerra de la Alpujarra: cabalgadas y esclavización de los moriscos en 1571", en Maria Marta Lobo de Araújo y Alfredo Martín García (coords.), Os marginais (séculos XVI-XIX), V. N. Famalicão, Edições Humus, 2018, pp. 147-162

Fernández Chaves, Manuel F. y Pérez García, Rafael M., "Notas sobre la destrucción de las comunidades moriscas malagueñas y su reconstrucción en la campiña sevillana, 1569-1610”, Áreas, 30 (2011), pp. 121-139.

Fernández Chaves, Manuel F. y Pérez García, Rafael M., En los márgenes de la Ciudad de Dios. Moriscos en Sevilla, Valencia, Universitat de València, Universidad de Granada, Universidad de Zaragoza, 2009, Biblioteca de Estudios Moriscos, 6.

García Pedraza, Amalia, Inventario de Protocolos Notariales. Granada, siglo XVI, Granada, Colegio Notarial de Granada, 2008.

Garrido García, Carlos Javier, "Las esclavas moriscas en el reino de Granada tras la rebelión de 1568-1571: cotización en el mercado y explotación laboral y sexual", eHumanista/Conversos, 6 (2018), pp. 325-345.

Garrido García, Carlos Javier, "La esclavitud de los moriscos capturados en la rebelión del reino de Granada: un fenómeno a corto plazo", Boletín del Centro Pedro Suárez, 26 (2013), pp. 79-107.

Garrido García, Carlos Javier, La esclavitud en el reino de Granada en el último tercio del siglo XVI: el caso de Guadix y su tierra, tesis doctoral defendida en la Universidad de Granada, 2011.

Garrido García, Carlos Javier, "La expulsión de los moriscos del reino de Granada de 1584. El caso de Guadix y su tierra", Miscelánea de Estudios Árabes y Hebraicos, Sección Árabe-Islam, 51 (2002), pp. 19-38.

Girón Pascual, Rafael M., Comercio y poder. Mercaderes genoveses en el sureste de Castilla durante los siglos XVI y XVII (1550-1700), Valladolid, Universidad de Valladolid, 2018.

Hurtado de Mendoza, Diego, Guerra de Granada, Bernardo Blanco González (ed.), Madrid, Castalia, 1970.

Jiménez Estrella, Antonio, Poder, ejército y gobierno en el siglo XVI. La capitanía general del reino de Granada y sus agentes, Granada, Universidad de Granada, 2004.

Jiménez Estrella, Antonio, "La alcaidía de la Alhambra tras la rebelión morisca y su restitución al quinto marqués de Mondéjar", Chronica Nova, 27 (2000), pp. 23-51.

Mármol Carvajal, Luis del, Historia del rebelión y castigo de los moriscos del reino de Granada, Javier Castillo Fernández (ed.), Granada, Editorial Universidad de Granada \& Tres Fronteras Ediciones \& Diputación de Granada, 2015, Monumenta Regni Granatensis Histórica/Scriptores.

Martín Casares, Aurelia, La esclavitud en la Granada del siglo XVI, Granada, Universidad de Granada, Diputación Provincial de Granada, 2000. 
Pérez García, Rafael M., "Moriscos en Antequera, 1569-1574”, Al-Qantara, 37, 1 (2016), pp. 75-110.

Pérez García, Rafael M., "El laboratorio ibérico de conceptos y prácticas sobre la esclavitud y los mestizajes: diversidad de experiencias, pueblos y cultura", en Eduardo França Paiva, Manuel F. Fernández Chaves y Rafael M. Pérez García (orgs.), De que estamos falando? Antigos conceitos e modernos anacronismos: escravidão e mestiçagens, Rio de Janeiro, Garamond, 2016, pp. 11-38.

Pérez García, Rafael M., Fernández Chaves, Manuel F., “La guerra de Granada entre guerra civil y «guerra justa»", en Miguel Luis López-Guadalupe y Juan José Iglesias Rodríguez (coords.), Realidades conflictivas. Andalucía y América en la España del Barroco, Sevilla, Universidad de Sevilla, 2012, pp. 229247.

Pérez García, Rafael M. y Fernández Chaves, Manuel F. "La infancia morisca, entre la educación y la explotación”, en Francisco Núñez Roldán (ed.), La infancia en España y Portugal. Siglos XVI-XIX, Madrid, Sílex, 2011, pp. 149186.

Ruiz Pérez, Ricardo, "El levantamiento morisco en tierras de señorío. El caso del marquesado del Cenete", en Chronica Nova, 19 (1991), pp. 291-336.

San Martín Vadillo, Ricardo, "Esclavos de Alcalá en tiempos de Carlos V", en Francisco Toro Ceballos (ed.), Carolus. Homenaje a Friedrich Edelmayer, Alcalá la Real, Ayuntamiento de Alcalá la Real, 2017, pp. 359-369.

Sánchez Ramos, Valeriano, El II marqués de Los Vélez y la guerra contra los moriscos, 1568-1571, Almería, Ayuntamiento de Vélez Rubio y Ayuntamiento de Berja, 2002.

Sánchez Ramos, Valeriano, "La guerra de las Alpujarras (1568-1570)", en Manuel Barrios Aguilera (ed.), Historia del Reino de Granada, Granada, Universidad de Granada y El Legado Andalusí, 2000, pp. 507-542.

Sanz Fuentes, María José, "Contribución de la ciudad de Écija y de los caballeros naturales de ella a la guerra contra los moriscos sublevados en el reino de Granada", en Miscelánea de estudios dedicados al profesor Antonio Marín Ocete, Granada, Universidad de Granada y Monte de Piedad de Granada, 1974, vol. II, pp. 983-999.

Spivakovsky, Erika, "Un episodio de la guerra contra los moriscos. La pérdida del gobierno de la Alhambra por el quinto conde de Tendilla (1569)", Hispania, 31 (1971), pp. 399-431.

Vincent, Bernard, "Les jesuites chroniqueurs récits de la guerre des Alpujarras", Chronica Nova, 22 (1995), pp. 429-466.

Recibido: $12 / 09 / 2018$

Aceptado: 30/03/2020 